\title{
The Construction of Collective Identity in Malaysian ESL Secondary Classrooms
}

\author{
Faizah Idrus ${ }^{1} \&$ Nas Idayu Mohd Nazri ${ }^{1}$ \\ ${ }^{1}$ Kulliyyah of Education, The International Islamic University Malaysia \\ Correspondence: Faizah Idrus, Kulliyyah of Education, The International Islamic University Malaysia, Jalan \\ Gombak, 53100, Kuala Lumpur, Malaysia. Tel: 60-361-965-384. E-mail: ifaizah@iium.edu.my
}

Received: August 9, 2016 Accepted: September 10, 2016 Online Published: September 13, 2016

doi: 10.5539/elt.v9n10p101 URL: http://dx.doi.org/10.5539/elt.v9n10p101

\begin{abstract}
This study seeks to identify the construction of collective identity in ESL classroom among students in a secondary school in Selangor, Malaysia. Identity construction can be helpful in supporting students academically and socially, especially in the English language classrooms. Being non-native speakers, students may have the tendency to feel isolated because of the limited knowledge in English. A qualitative investigation was employed and the samples comprised of 12 secondary students from Sekolah Menengah Kebangsaan Jeram, Kuala Selangor. In-depth interviews were carried out with the respondents. The results revealed that when constructing their personal identities, individuals may want to identify themselves with the mutual interest of the groups they are part of. Identifying oneself with a group not only means wanting to be accepted, but also adhering to having mutual identities and values of the group. Therefore, the current study seems to confirm the finding of previous studies where researchers stated that the identity of an individual is defined by its majority group with whom the individuals share the physical environment and the territory they inhabit.
\end{abstract}

Keywords: collective identity, ESL classrooms, ELT, identity construction, qualitative study

\section{Introduction}

\subsection{English as a Second Language in the Malaysian Setting}

In the English as Second Language settings like Singapore, Malaysia and the Philippines, ESL learners may have the opportunities to use English outside the classroom. However, in Malaysia, although the second language used is English, many students especially the "Malays are very shy and afraid to speak English with other friends regardless of their cultures" (Malay Mail, 2015, p. 1). Attempts to use English outside the classroom are seen by others as being westernized and having the intention to abandon the use of Malay language, the official language of Malaysia. Those who speak English are often seen as arrogant, less Malay and not proud of their own mother tongue. This is perhaps the reason why many students do not respond to teachers' advices to use English outside the classroom. Students are also afraid of using broken English. In this case, since language and identities are interrelated, teachers seem to dismiss the needs to mix students of different cultural identities so that their use of English will not distant, offend and annoy the member of the local group (Idrus, 2012). Students need to build their shared identities among friends in the classroom so that they can speak freely and not to be afraid for example to use wrong grammar. This can be done by doing more English activities in the classroom for the students to build their identities well. Another question is about how students portray their identity when they are using the English Language; do they associate themselves with a collective sense of identity amongst their peers or does personal identity reign?

Many researchers reported on the construction of identity, but there were little empirical studies on the construction of collective identity in ESL classroom among students in secondary school. Therefore, the purpose of this study is to identify factors contributing to the construction of collective identity in ESL classroom among students in secondary school in the multicultural Malaysian setting. Thus, the purpose of this paper is to examine the possibilities on how Malaysian youth construct their personal identity in ESL classroom Additionally, it is also to shed some lights on how secondary school students perceive their identity and to investigate possible ways to enable students to work closer with each other in English classroom despite their differences.. Thus, the questions below frame the direction of the study. 
1) What is personal identity to the students?

2) How do they perceive their own identity in the classroom?

3) What are the factors contributing to collective identity among secondary school students in ESL classroom?

\subsection{Significance of the Investigation}

The researchers hope that the findings of this study will assist ESL students to communicate better in the society and help them to relate themselves much more with the people in the community they live in so they will not feel out of place. Furthermore, the results and suggestions or recommendations of the study are hoped to facilitate English language teachers to be more alert towards the achievement of the students in ESL classroom by understanding how these students construct their identities during the teaching and learning processes.

\section{Review of Relevant Literature}

The process of trying to pin down the term identity is extremely complex. Many people and even the scholars have attempted to define the term identities. As mentioned by Ang (2011), identity is an ever changing concept and it is constantly being shaped and conditioned by the environment and culture one is born into, which means one's identity is not fixed at any time in any circumstances. This shows that the word identity itself varies in meanings depending on how people see it. Hall and Gieben (1991), admit that identity is "too complex, too under-developed, and too little understanding in contemporary social science to be definitely tested". (p. 23). Identity may be understood as "who we are", such as education that we have received, culture that we have been taught, and society that we have lived in, which plays an important role in developing our identity. Apart from that, in this social world, individuals' identities play vital roles in their development and formation of relationships with themselves and with others. McCarthy et al. (2002) assert that "identity matters because whatever shape it is, it is an aspect of how humans make sense of the world and their experiences in it, including their experience with text" (p. 228).

In addition, it is important to know that identities often change. To understand identity, it is pivotal to remember that one always go through constant cultural socialization. This socialization process helps us respond to and cope with various types of stress they encounter. When speaking about socialization activities, the other two types of identities which play important roles in shaping our identities are collective identity and shared identity. Collective identity appears when individuals feel a sense of belonging to a group where they participate in social activities and according to Cerulo (1997), it internalises the qualities of 'we-ness' and being united within the boundaries of shared attributes. Whereas shared identity concludes that the individual will have the same characteristics with one or more people. It is more likely to happen when they have many defining characteristics and qualities as others.

\subsection{Collective Identity}

A collective identity is actually a sense of recognition and attachment to certain groups of people. The application of a collective identity depends on the level of acceptance by whom it is applied to. Additionally, collective identity can also be described as shared identity. When speaking about sharing, it obviously contributes to positive feelings among the individuals. This is also agreed by Polleta and Jasper (2001) who stated that "unlike ideology, collective identity carries with it positive feelings for other members of the group" (p. 117). Furthermore, in collective identity, individuals gain benefits by identifying themselves as being part of a collective identity, because as what Olson (1965) asserts, "shared interest are simply not enough to motivate students to participate in a movement", but rather the sense of belonging is also one of the important thing in collective identity. This indicates that when individuals feel positive being affiliated with a certain group, the form of movement, the bonding they have will make their relationship stronger. Sharing the same interest and attributes among the group members indirectly shows that the connection among them is strong and thus will make the bonding lasts longer (Muller, 2008).

\subsection{Shared Identity}

Shared identity describes the attitude towards the team members and the we-ness (Cerulo, 1997) of the team. The ability to communicate with others is one of the most important human function, yet communication is not always investigated from a social perspectives. As what is stated by Clark and Marshall (1981), a shared context makes communication more efficient, decreases the probability of misunderstandings (Cramton, 2001) and increases mutual understanding (Brezillion \& Araujo, 2005). The forging of shared identity can actually influence the behavior which leads to rebuilding of solidarity and mutuality. It is therefore timely for us to go beyond the arguments about whether diversity is good or otherwise and accept that it will increasingly be part of our individual and communal experiences. The challenge is not how one feels about it but rather how one 
responds to it. Similarly, Idrus (2014) asserts that shared identity can easily be understood as "a set of individuals' sense of belonging to the group they belong to. The concept is like when one is involved in social activities, the individual either feels part of the group which he or she shares the same identity or being isolated from the group. Idrus (2014) continues by saying that from shared identity, one may construct his or her personal identity. Shared identity, in particular, features in a wide variety of arguments. With shared identity, there will be a reduction of security dilemma. This is when one feels secured and has a sense of belonging, the dilemma begins to erode and disappear. Idrus (2012) on the other hand mentions that in order to construct shared identity, teachers and students have to have an open minds towards the cultures, beliefs and customs of others around them.

\subsection{Identity Construction}

Review of literature has revealed that identity construction can be engaged as a reference to the collective self-awareness that a group embodies and reflects. Identity is always associated to culture, social and other vague elements such as location, homes, customs and the like. Although there are many who wrote on identity construction, conformity of what identity actually means remains unsolved. The meaning of the term identities are seen as synonymous to a "stable core self" (Hall, 1996) to dynamic, contradictory, and multiple dimensions of a person. Ha (2008) argues that there is different conceptions of identities between West and East. Western scholars tend to perceive identities as "hybrid and multiple" (p. 64), whereas Eastern scholars see identities as related to a sense of belonging. These two perceptions show that these could be affected by the different cultures they own in their particular places. Different cultures and situations afford varying perceptions regardless of who and where they are from.

Despite the differences, recently English language learner identities have been addressed and studied from a structuralism point of views which conceptualize identities as multiple, diverse, dynamic and contradictory. Several studies have illustrated the multidimensional and non-unitary natures of learner's identities. One of the most cited studies is from Norton (2000). One of her participants, "Martina" has multiple identities as an immigrant and a language learner. She never felt comfortable speaking English due to certain reasons. However, her identity as a mother allowed her to engage in a language conversation with her landlord when she was accused of breaking a lease agreement. This shows that the situation that one encounters sometimes can force him or her to do something that he or she never expected to happen. Eventually, people will get used to that situation and start to treat it as a routine in their daily lives.

Other studies, such as Kramch (1993), Norton (2000) and Lee (2003) see bilingual identities as dynamic and changing over time. Kramch (1993) asserts that sociocultural identities are flexible and deterministic in the constructs which ESL students bring to the classroom and then remain unchanged at the end of a lesson or course Wenger (1998) argues that identity should be seen as an ongoing process of negotiating the self. According to Fearon (1999) identity formation is fluid and complex rather than clear-cut and solid. Identities can be changed over time depending on the surrounding and environment. This is why the formation of identity is said to be not static and rather complex.

Hence, it can be summarized that the studies on the identities are multidimensional, a site of struggle, fluid and changing over time. Learning a second language does not mean you have to abandon the ethnic identities. But to upgrade yourself by having more language that you can master which can give you many benefits in your future.

\section{Methodology}

\subsection{Research Design}

In this investigation, a qualitative research design was employed. The research is aimed at examining the construction of collective identity in ESL classroom among students in secondary school and Group Semi-Structured interviews were used to gain in depth understanding of the central phenomenon. The researchers used purposive sampling, in which the 12 students had been selected from SMK Jeram, Selangor. According to Neuman (2007) purposive sampling begins with specific perspectives in mind that he or she wishes to examine and then seeks out research participants who cover that full range of perspectives. In sum, the researchers utilized a purposive sampling to obtain data from the respondents who fulfilled the characteristics required for the research. The samples were chosen as they could represent the population and could help the researcher to understand the construction of collective identity among them. The number of samples for this study is adequate as the number of samples for qualitative research could range from 1 to 40 (Creswell, 2005).

\subsection{Participant}

For the purpose of this study, twelve Form 5 students from Jeram Secondary School were chosen to answer the 
interview questions. Spending about 2 months to gather the data from the students in two groups, which consisted of 6 students per group allowed the researchers to obtain rich data. Since majority of the students in SMK Jeram are Malays, the respondents were all Malays and Muslim. The school is situated at Jalan Simpang Tiga which is in the rural area of Kuala Selangor. The population of this area is a combination of $85 \%$ Malays, $10 \%$ Indians and only $5 \%$ Chinese. SMK Jeram was accessible to the researchers at the point of investigation. Appropriate identification of research participants is critical to the science and practice of psychology, particularly for generalizing the findings, making comparisons across replications, and using the evidence in research syntheses and secondary data analyses.

\subsection{Background of the Respondents}

Table1 below shows the information of the12 respondents obtained from different classes. The respondents of this study were 4 male and 8 female students aged 17 years old. They were mixed ability students from different level of classes. The students are referred to in this study as R1, R2, R3, R4, R5, R6, R7, R8, R9, R10, R11 and $\mathrm{R} 12$ to ensure confidentiality. Jeram is a short form for Sekolah Menengah Kebangsaan Jeram while ' $F$ ' and ' $M$ ' are labelled as Female and Male. The students were given a consent form each to be filled so that they understood the procedure of the research.

Table1. Demographic information of respondents

\begin{tabular}{clllll}
\hline Respondent & Race & Age & School & Stat & Gender \\
\hline R1 & Malay & 17 & Jeram & Selangor & $\mathrm{M}$ \\
R2 & Malay & 17 & Jeram & Selangor & $\mathrm{M}$ \\
R3 & Malay & 17 & Jeram & Selangor & $\mathrm{M}$ \\
R4 & Malay & 17 & Jeram & Selangor & $\mathrm{F}$ \\
R5 & Malay & 17 & Jeram & Selangor & $\mathrm{F}$ \\
R6 & Malay & 17 & Jeram & Selangor & $\mathrm{F}$ \\
R7 & Malay & 17 & Jeram & Selangor & $\mathrm{M}$ \\
R8 & Malay & 17 & Jeram & Selangor & $\mathrm{M}$ \\
R9 & Malay & 17 & Jeram & Selangor & $\mathrm{F}$ \\
R10 & Malay & 17 & Jeram & Selangor & $\mathrm{F}$ \\
R11 & Malay & 17 & Jeram & Selangor & $\mathrm{F}$ \\
R12 & Malay & 17 & Jeram & Selangor & $\mathrm{F}$ \\
\hline
\end{tabular}

\subsection{Sampling Procedures}

The instrument used for this study was a set of interview questions. The first task answered the question about the understanding of the word identity and the second research question focused on the factors contributing to personal identity. The interviews were conducted after school hours which took approximately around 1 hour for each group interview.

\subsection{Analysis and Preparation of Data}

The responses from the respondents were analysed using the thematic analysis where all of the answers were categorized into themes to facilitate easier understanding. As mentioned by Braun and Clark (2006), thematic analysis is a method for identifying, analysing, and reporting patterns (themes) within data. It minimally organizes and describes our data set in (rich) detail. Researchers and readers will easily find the result according to the thematic analysis done and thus will make the data organized. The interviews were conducted in two group discussions and were recorded using an MP3 recorder. The recorded audio was transcribed in discourse units to facilitate the process of transcribing. The responses from the interviews were then coded through coding identifier as follows: 


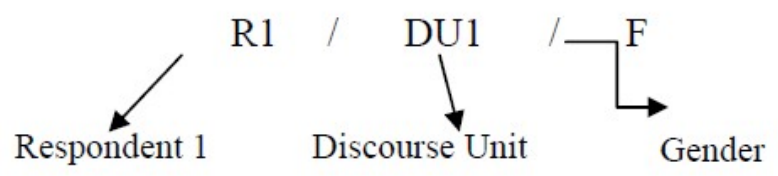

Coding identifier for the respondents

\section{Analyses and Discussion}

From the data generated via the in-depth interview with the respondents, a few themes emerged. They are:

1) Manglish

2) Personality

3) Self-interest

4) Habits of the Students

5) Methods of learning

6) Acceptance and Respect

\subsection{Language Use - Manglish}

Language use in any community represents their identity. However, this element is even more complicated in multicultural settings such as Malaysia. Respondents were asked about their language used in the classroom. Four of them stated that classroom was one of the places that they were free to express themselves. To them, when people speak a language, it indirectly shows who they are. For examples, R9 stated, "The second scenario" (R9/DU165/F), and also agreed by R10, "The second scenario too" (R10/DU169/F), together with R11, "For me, second one too" (R11/DU171/F) and R12, "Second one" (R12/DU175/F). Second scenario was directed to a choice given to them on the way the felt when speaking the English language in the classroom, which is Manglish (A combination of Malay and English, Chinese and English or Tamil and English). Other choices were 'English only' and 'Malay only'

When the researchers asked why Manglish represented their identity, one of the respondents expressed that Manglish showed "who you are". R12 stated that, "Because it shows your true self and that's all." (R12/DU177/F). From the way the respondents expressed their opinion on this subject matter, they generally perceive that identity is something that represents people. The rest of the respondents as a whole, believe that identity is 'who you are and how you want others to see you'. Thus, Manglish is the medium in that they truly felt connected.

\subsection{Personality - Characteristics, Inside and Outside}

When asked about what identity really is to them, most of the respondents seemed to struggle to provide an answer. Typically, they would say that identity is personality. Although the researchers gave several scenarios which depicted and captured the essence of identity, they were still attached with their understanding that identity is personality. In actual fact, identity is actually a broad term that can be understood in many ways. It is like a huge umbrella that comprises variety of understandings based on how the individuals perceive it. R1 had this to say about identity,

someone's personality on how do you describe them and how do you see them inside or outside. Like for instance, if it's outside, you can see how their physical traits and for inside you can see how he handles some of his stuff or how does he handle his life. Maybe some kind of, what his traits like you see...is he electromaniac or something like that. (R1/DU4/M).

Another respondent also had the same opinion about identity. R3 stated that identity is personality, "I think identity is personality, about someone...just like Iman said, aaa ... how we describe the person, like that." (R3/DU8/M). Similarly, respondents R4, R5 and R6 said that identity is about characteristics and attitude. They had the same opinion as R3 who mentioned that identity is the personality of and about someone. For instance, R5 and R6 said, "As for me, identity is like someone's character, personality, just the same like Iman" (R5/DU11/F), and agreed with the statement, "I think identity is self-personality of someone. Like the attitude that we can see." (R6/DU13/F) 
From these responses, it clearly shows that the respondents are confident in thinking that personality is something that be concluded as identity.

\subsection{Identity is Related to Self-interest}

Besides the respondents' opinion on what identity is to them, the researchers also asked whether identity is similar to likings, hobbies, habits and the way someone looks. Surprisingly, the respondents responded by saying that it is related to self-interest which are people's likings and hobbies which can then develop into someone's identity. Again, the respondents were eager to say that personal likings and hobbies were actually their identity. They said both of these elements could actually describe their identity in detail. R1 said, “... I agree when you say that identity is the same like interest, hobbies" (R1/DU17/M). This is also in tandem with R2 and R3 who stated that, "Aaa, to me ... I think hobby ... we can see the identity with the hobby. So, for example if you like playing badminton, then you are labelled as an active person."(R2/DU19/M). "I think it is. When we are doing our hobbies, like playing games, we are described as gamers." (R3/DU21/M)

As mentioned by the respondents, most of them clearly had different understanding of what identity is. They perceived identity based on what they learned throughout their journey as students and also from the knowledge they gained from their teachers. To them, the word identity was aptly described as what was it people had in themselves specifically their personality. To reiterate, the word identity itself is a huge term that can be understood in general. Although the respondents were quite confused about the word identity at the beginning of the interview, they seemed to be able to grasp the concept of identity towards the end of the interview sessions.

\subsection{Habits/Hobbies of the Students}

The second main intention of the investigation was to identify the factors contributing to collective identity among secondary school students. The first pre-determined theme discovered by the researcher was habits of the students. According to Sardar (2011), habits can be divided into three types which are motor habits, intellectual habits and habits of character. In this case, the researchers discovered that the respondents shared the third type which is habits of character. When asked about their hobbies or things that they always do daily, it is not surprising to note that most of them shared similar interests. For instance, the respondents were eager to share their favorite activities in terms of what they normally did at home and what they loved to do. Moreover, most of them said that they loved playing games, reading books and novels, and watching movies. R1 shared her habit with the researcher. She said,

The most obvious one is sleeping, of course. Nobody can go a day without sleeping. And second one is sleep again, and the third is playing games. Next is eating, yes. I love to eat. And then the fifth is, read a lot of English magazines or articles or facts (R1/DU68/M).

Another respondent also shared the same hobbies and habits. This is probably due to the fact that these two respondents were actually close friends. R2 said, “... my hobbies are sleeping playing games, and playing games until I fell asleep." (R2/DU70/M). This is similar to what R3 said, "My hobby is playing games" (R3/DU72/M). As for the female respondents R4, R9 and R11, their habits differed from the male respondents although some of them shared the same things as male respondents, "I like to listen to music and play games. The type of music that I like is English R\&B music." (R4/DU74/F). R9 added, "Other than reading novel, I love to watch movies and also sleep." (R9/279/F) and this is similar to R11, "I love to watch K-Drama and TV shows, movie ..." (R11/305/F).

For them, sharing the same hobbies and at other times habits, made them closer and more comfortable with each other. They even asked other respondents who were also their friends about their own favorite things since they always shared experiences with each other. From the researcher's observation, their friends also acknowledged their favorite hobbies and they seemed to be sharing everything together. Their characters revealed that they have many similarities with one another without even knowing it. With this new found information about their friends, they are likely to be much closer to one another.

\subsection{Methods of Learning}

Method of learning is one of the factors contributing to collective identity among the students. One of the ways in which the respondents learned the English language is through presentations and group discussions among themselves. They preferred these two methods more than other approaches of learning English. Some of the respondents said that they liked to talk and through presentations they got the chance to speak and enhance their speaking skill. One of the respondents said, "“'Yes I like presentation too because I like to talk in front of people. But normally our teacher will do drama the most" (R2/DU109/M). R3 supported what R2 said, "Presentation. Like R2 said. Because we're in the same class" (R3/DU113/M). R5 gave her reasons why she liked presentation 
as a method of learning. She said, "Same, presentation. Because we get the chance to speak in front of the class" (R5/DU115/F). Another respondent also thought that by doing presentations, it made her understood more about what she had learned and presented. She had this to say, “"Presentation. Because it makes me understand more about what I'm presenting" (R6/DU116/F). One of the respondents even described how they usually did their presentation in the class where they had to act as the teacher and taught others regarding a particular topic. He said, "We have to be the young teachers and teach our classmates about the topic, sometimes we traded places with the teacher. Sometimes our teacher will be the student and the students are the teacher" (R1/DU111/M).

From this statement we can conclude that the respondents loved learning English through speaking and communicating, as they believe that they could improve their command in English and at the same time they feel appreciated by the teacher. This clearly shows that most of them really love doing class presentations which made them improved their skills in English. In short, presentation is indeed one way of integrating different types of skills and it is proven to be one of the best ways to promote English language communication skills.

\subsection{Acceptance and Respect}

Acceptance and respect emerged as part of the themes in this investigation. In order to feel accepted and belonged to one's group, the value of acceptance and respect are paramount. When these two values appear, the bond that they have created tended to be stronger and one can feel the sense of belonging to that particular group. Most of the respondents said that they liked to cooperate with other friends when it came to doing English homework. From that, they could discuss many things and corrected each other whenever needed. R1 had this to elaborate, "For me, they are talkative traits la. If they are talkative and they like to talk a lot, unstable like me, I would be gladly work with them" (R1/DU140/M). This is supported by R2, "Because they have same interest like me. They like to cooperate and having same characteristics" (R2/DU141/M).

Besides that, when the researcher asked about how they would choose their group member when it came to doing group activities in classroom, most of them preferred those who have similar characteristics and traits with them to work with. R1 said, "No, like all my classmates are talkative and I can work with all of them and we have the same traits like we like to laugh at each other and we like to pick on each other. And that's what make us "click" to each other" (R1/DU143/M). This is then supported by R3 who said, "I will choose someone who has same hobbies with me and he has many stories to tell me" (R3/DU145/M).

However, there were also respondents who looked for those who have good command of the English language and were willing to teach their friends. For them, having the same characteristics was not the issue but positive attitude is a must when it came to learning. R4 said she needed someone whose English is better than hers, "Someone who can teach me because I'm not really good in English and someone who is confident" (R4/DU146/F). R5 elaborated more on this issue. She said, "Someone who can give cooperation and someone who has confident to communicate in front of others" (R5/DU148/F). Surprisingly, one of the respondents said that she would prefer someone who is hard working since she herself was quite 'laid back' when it came to doing the activities in classroom, "I will choose those who are hardworking because I'm lazy. I will help to contribute the ideas" (R6/DU149/F).

This clearly shows that the value of acceptance and respect among friends are two important elements in constructing collective identity among the respondents. When these two elements failed to be inculcated, the collective identity among them will be impaired or cannot be realized.

The understanding of what identity means may differ for everyone depending on one's level of knowledge and education. The present study attempted to discover how students in secondary school perceived identity and what were the factors contributing to collective identity among the students.

In response to the first question, the word identity is mainly understood as personality and self-interest. Findings show that identity could be seen through one's personality and self-interest in terms of hobbies and likings. Each of the students interviewed basically developed a similar understanding about identity and the researcher concluded the respondents' understanding on identity were perceived through their learning and experiences being in the school.

Based on the findings, the researcher found that teenagers are in process of shaping their identities, while living in between cultural social contexts. Dowling (2011) also states that, "this makes the students in the study fragile and in the process of finding and searching their identities" (p. 11). According to Cerulo (1997), to construct their identities, such students have cultural references from their home or at school, and at the same time, of different social groups. However, the result of this study shows that individuals specifically teenagers are still confused about what identity actually is and the construction of collective identity is based on the shared 
knowledge that makes them negotiate with other individuals or groups of people.

From the interviews conducted in this study, most of the students found that they were likely to be more 'connected' in groups or friends from the same interest in their classroom decision making. Most of them perceived identity as personality, self-interest and choice of language use. In their perspectives, identity could be understood and seen in someone's personality, self-interest and the choice of language use. For them, identity is something that they can conclude from the characteristics of a person, his or her self-interest and the language uses. The students seemed to follow the concept of identity from the first respondent's answer and then elaborated it from their own understanding. Basically from all the responses, they agreed that identity could be perceived by just knowing about someone's personality, what he or she likes and the language used by the person. However, their understanding about identity was somehow contradictory to that of the study by Ang (2011) which indicated that identity is a concept of ever changing and it is constantly being shaped and conditioned by the environment and culture the people were born into which also means our identity is not fixed at any time in any circumstances. According to most personality theories, the individual's type is inborn and does not change. However, individuals can develop traits and habits that contradict to the description of their type and thus will make it change according to situations and surroundings. In this case what the researchers wanted to highlight was the fact that personality and identity are two different things, which give us different concept of understanding.

To make it clearer, theories of personality imply that personality is biologically based, whereas theories by Bandura (2008) from Social Learning Theory emphasized the role of nurture and environmental in personality. While for identity, it is actually the concept of oneself of what one gives yourself, for example, what one stands for and are to know to stand for. This is parallel with the study of Wenger (1998) and Hall (2000) who argue that identity should be seen as an ongoing process of negotiating the self. The confusion of the students about what actually identity is logical since the word identity itself is very complex.

\subsection{Factors Contributing to Collective Identity among Students in ESL Classroom}

Based on the findings, the researchers found that factors contributing to collective identity among the students are heavily influenced by the students' daily activities in school and in the classroom. In this case, there are four factors that emerged in the study which are habits (as in what they always do), mutual language learning (choice of language they use in ESL classroom), method of learning English language and acceptance and respect (the sense of belonging in a group).

From the result, collective identity among the individuals can be achieved when they share similar things regardless of who they are. The factors above confirmed the study by Muller (2008) in which he claims that sharing the same interest and attributes among group members indirectly shows that the connection among them is strong and thus will make the bonding lasts longer. For this reason, having to knowhat there are those who own the same qualities and attributes like themselves is actually giving them a warm feeling where they get to share things and contribute to a good relationship with others. This is supported by Polleta and Jasper (2001) who indicate that "unlike ideology, collective identity carries with it positive feelings for other members of the group" (p. 117).

The sharing of same interest and attributes among the group members is indeed making the bonding among them stronger and it is in agreement with the study done by Clark and Marshall (1981), in that they said that a shared context makes communication more efficient, decreases the probability of misunderstandings, and increases mutual understanding (Brezillion \& Araujo, 2005) among group members. Apart from that, among all those factors, mutual language learning is one of the factors that actually gave another insight where Malay and English are constantly being used among the students. In this case, Malay and English have been seen as the glue that binds people of diverse backgrounds in Malaysia.

\section{Conclusion}

Identity can be subjective due to its situation and environment. Therefore, in this case, teachers as educators in schools need to play an important role in shaping the students to be active and responsible citizens by developing shared or collective identity to facilitate their teaching practices. Besides, through collective identity, the teachers can help to inculcate good values in the students. People can be different and unique in their own ways, yet still have much in common among them. Such realizations help them to accept differences among them and aid them in minimizing and probably eliminating prejudices and racism. These realizations also assist students to accept and respect people regardless of what backgrounds they come from and the various cultures they bring with them. This is what citizens of Malaysia have been practising since they live in a multicultural society. As people learn to accept differences and similarities among themselves, they can work and get along with others better (Idrus, 
2014). One will begin to see other's viewpoints and individuality. From that, one can indirectly shape his or her own identity by mingling with people of diverse culture who live in the same society. One's self-esteem is boosted as soon as he or she is recognized and accepted for his or her own individuality.

\section{References}

Ang, I. (2001). On Not Speaking Chinese: Living Between Asia and the West. London and New York: Routledge.

Bandura, A. (2008). Toward an Agentic Theory of the Self. In H. March, \& R. Craven (Eds.), Self-Processes, Learning and Enabling Human Potential.

Braun, V., \& Clarke, V. (2006). Using thematic analysis in psychology. Qualitative Research in Psychology, 3(2), 77-101. http://dx.doi.org/10.1191/1478088706qp063oa

Brézillon, P., \& Araujo, R. M. (2005). Reinforcing shared context to improve collaboration. Revue D'intelligence Artificielle, 19, 537-556. http://dx.doi.org/10.3166/ria.19.537-556

Cerulo, A. K. (1997). Identity Construction: New Issue, New Directions. Department of Sociology. New Jersey. http://dx.doi.org/10.1146/annurev.soc.23.1.385

Clark, H. H., \& Marshall, R. C. (1981). Definite Reference and Mutual Knowledge (pp. 12-60). Cambridge University Press.

Cramton, D. C. (2001). The Mutual Knowledge Problem and Its Consequences for Dispersed Collaboration. School of Management, George Mason University, 12(3), 346-371. http://dx.doi.org/10.1287/orsc.12.3.346.10098

Creswell, J. W. (2007). Qualitative inquiry and research design: Choosing among five approaches (2nd ed.). Thousand Oaks: Sage Publications

Dowling, J. S. (2011). Constructing Identity Identity Construction. Thesis, Georgia State University.

Erikson, E. H. (1970). "Identity crisis" in perspective. In E.H. Erikson, Life history and the historical moment. New York: Norton, 1975.

Faizah, I. (2012). The Construction of Shared Identity in the Malaysian Upper Secondary Literature Classrooms. Unpublished PhD Thesis, The University of Nottingham, UK.

Faizah, I. (2014). Facilitating the Construction of Shared Malaysia Identity Through The Teaching of Literature. International Islamic University Malaysia.

Fearon, J. (1999). What is Identity (as we now use the word). Unpublished Manuscript. Stanford University.

Ha, P. L. (2008). Teaching English as an international language: Identity, resistance, negotiation. Clevedon: England Multilingual Matters

Hall, S. (2000). 'Who Needs Identity?’ In P. du Gay, J. Evan, \& P. Redman (Eds.), Identity: A Reader (pp. 15-30). IDE: Sage Publications Inc.

Hall, S., \& Gieben, B. (1991). The Formations of modern society. Polity Press.

Kramsch, C. (1993). Context and culture in language teaching. Oxford: Oxford University Press.

Lee, S. K. (2003). Exploring the relationship between language, culture and identity. GEMA Online Journal of Language Studies, 3(2).

McCarthy, S., \& Moje, J. (2002). "Identity Matters". Reading Research Quarterly, 37(2), 228-238. http://dx.doi.org/10.1598/RRQ.37.2.6

Moje, E. B. et al. (2004). Working Toward Third Space in Content Area Literacy: An Examination of Everyday Funds of Knowledge and Discourse. Reading Research

Muller, E. R. (2008). Agency, Language Learning, and multilingual spaces. Multilingual, 31, 12-31.

Neuman, W. L. (2007). Basics of social research: Qualitative and quantitative approaches (2nd ed.; International ed.). Boston, Mass; London: Pearson, Allyn and Bacon.

Norton, B. (2000). Identity and Language Learning: Gender, Ethnicity, and Educational Change. Harlow: Longman/Pearson.

Olson, M. (1965). The Logic of Collective Action. Cambridge, MA: Harvard Univ. Press

Polletta, \& Jasper, J. M. (2001). Collective Identity and Social Movements. Annual Review of Sociology, 27, 283-305. http://dx.doi.org/10.1146/annurev.soc.27.1.283 
Sardar, M. A. (2011). Learner Identity in Second Language Education. The Southeast Asian Journal of English Language Studies, 18(2), 13-23.

Wenger, E. (1998). Communities of practice: Learning, meaning, and identity. Cambridge, England: Cambridge University Press. http://dx.doi.org/10.1017/CBO9780511803932

\section{Copyrights}

Copyright for this article is retained by the author(s), with first publication rights granted to the journal.

This is an open-access article distributed under the terms and conditions of the Creative Commons Attribution license (http://creativecommons.org/licenses/by/4.0/). 